\title{
Prevalence and incidence rate of tuberculosis among HIV-infected patients enrolled in HIV care, treatment, and support program in mainland Tanzania
}

\author{
M. Majigo ${ }^{1 *}$ (D, G. Somi ${ }^{2}$, A. Joachim¹, J. Manyahi', J. Nondi², V. Sambu², A. Rwebembera², N. Makyao²,
}

A. Ramadhani', W. Maokola'2, J. Todd ${ }^{3}$ and M. I. Matee ${ }^{1}$

\begin{abstract}
Background: Despite improvements in access to antiretroviral therapy (ART), mortality in people living with human immunodeficiency virus (PLHIV) is still high and primarily attributed to tuberculosis (TB) infection. In Sub-Saharan Africa, approximately $80 \%$ of HIV-related mortality cases are associated with TB. Relatively little is known about the incidence of TB among PLHIV in Tanzania and the determinant factors. We report the prevalence and incidence rate of confirmed TB and determine association with selected demographic and program-related factors based on data in the national HIV care and treatment program from 2011 to 2014.

Methods: We used the Tanzania National AIDS Control Programme database to obtain information on all HIV clients enrolled in the HIV care and treatment program between January 2011 and December 2014. We analyzed retrospective cohort data to assess the prevalence and TB incidence rate per 1000 person-years. A multivariable Cox proportional hazards regression model was used to estimate hazard ratios and $95 \%$ confidence intervals for putatively associated factors.

Results: Over 4 years, there were 22,071 confirmed cases of pulmonary TB in 1,323,600 person-years. The overall TB incidence was around 16.7 (95\% Cl 16.4-16.9) cases per 1000 person-years. The annual incidence rate decreased by $12.4 \%$ from $17.0(95 \% \mathrm{Cl} 16.5-17.4)$ in 2011 to $14.9(95 \% \mathrm{Cl} 14.5-15.4)$ in 2014. The TB incidence rate was higher in persons not using ART and in males than in females. The incidence of TB was higher in patients with advanced HIV disease and decreased with increasing age. The overall prevalence of TB was $2.2 \%$, with a peak prevalence of $2.5 \%$ in 2013 and was higher among children < 15 years (3.2\%) in the same year.

Conclusion: The study found an overall decrease in the incidence of TB in PLHIV. Our results emphasize the need for early initiation of ART and the provision of TB preventive therapy for those PLHIV without active TB after intensified TB case-finding.
\end{abstract}

Keywords: Tuberculosis, HIV, Incidence of tuberculosis, Antiretroviral therapy, Collaborative TB/HIV

\footnotetext{
* Correspondence: mmajigo@gmail.com

'Department of Microbiology and Immunology, School of Medicine,

Muhimbili University of Health and Allied Sciences, Dar es Salaam, Tanzania

Full list of author information is available at the end of the article
}

(c) The Author(s). 2020 Open Access This article is licensed under a Creative Commons Attribution 4.0 International License, which permits use, sharing, adaptation, distribution and reproduction in any medium or format, as long as you give appropriate credit to the original author(s) and the source, provide a link to the Creative Commons licence, and indicate if changes were made. The images or other third party material in this article are included in the article's Creative Commons licence, unless indicated otherwise in a credit line to the material. If material is not included in the article's Creative Commons licence and your intended use is not permitted by statutory regulation or exceeds the permitted use, you will need to obtain permission directly from the copyright holder. To view a copy of this licence, visit http://creativecommons.org/licenses/by/4.0/. 


\section{Introduction}

Tuberculosis (TB) and human immunodeficiency virus (HIV) co-infection is a significant public health problem worldwide [1-3]. The lifetime risk of developing active TB among people living with HIV (PLHIV) maybe 20 times higher than in people without HIV [4]. Tanzania is among the 30 countries with high TB burden and TB and HIV co-infection in the world [5]. The National Tuberculosis and Leprosy Programme annual report of 2017 indicates that about $31 \%$ of all TB-notified cases had co-infection with HIV [6]. Despite the increased access to antiretroviral therapy (ART), mortality in PLHIV is still high, and TB is the leading cause of mortality [79]. Some studies found that TB preventive therapy by isoniazid reduces the incidence of TB in HIV-infected patients $[10,11]$. Conversely, some studies have reported an unacceptably high incidence of TB after ART initiation as a result of immune reconstitution [12, 13].

In 2004, the World Health Organization (WHO) formulated an interim policy to guide member states in implementing collaborative TB/HIV activities [14] and further addressed the requirement for collaborative effort to address the burden of TB and HIV [15]. Subsequently, the Ministry of Health in Tanzania formed a national TB/HIV coordinating body in 2005 for delivering integrated TB and HIV services to reduce the burden of TB in PLHIV [14]. In these collaborative activities, screening for HIV among TB patients occurs in the TB clinics, likewise, the screening for $\mathrm{TB}$ at HIV care and treatment clinics. The country recommends TB preventive therapy to be part of the package of care for PLHIV. All HIV-positive individuals who screen negative for active TB are eligible for isoniazid preventive therapy for 6 months [16]

Previous reports from analysis of data collected between 2004 and 2012 in Dar es Salaam, the largest city in Tanzania, reported the TB incidence rate of 7.9/100 person-years before ART initiation and 4.4/100 personyears for patients receiving ART [17]. However, the reported TB incidence rates among HIV-infected patients before and after ART initiation were from HIV-infected cohort in the largest city in the country, which might not reflect the country-wide incidence rates. Also, the incidence rate might change with time, taking into consideration the implementation of collaborative TB and HIV activities. We, therefore, analyzed data in the national HIV care and treatment program collected from 2011 to 2014 to determine the country-wide incidence of TB and among PLHIV related factors.

\section{Material and methods}

\section{Design, setting, and population}

The descriptive-analytical study of retrospective cohort data is routinely collected between 2011 and 2014 at
HIV service delivery clinics and archived in the National AIDS Control Programme database. The data included information from all clients attending HIV care and treatment services, as stipulated in the national program for HIV management [16]. All HIV patients in Tanzania receive the same quality of care and treatment services at care and treatment clinics (CTC). The clinics have been set up, in both public and private hospitals, health centers and dispensaries, throughout Tanzania. An integral part of the delivery of care and treatment is to ensure that effective monitoring and evaluation of the HIV program takes place.

\section{Care and treatment service}

Provision of quality HIV care and treatment service was guided by the national HIV/AIDS care and treatment guideline [16]. Patients eligible for ART had baseline CD4 counts below 200 cells $/ \mathrm{mm}^{3}$ regardless of WHO stage or baseline CD4 counts between 200 and 350 cells/ $\mathrm{mm}^{3}$ and be in baseline WHO stage 3 or 4 or baseline WHO stage 4 regardless CD4 counts. Also, all adult patients with confirmed TB status during clinic enrolment were eligible for ART. Before the initiation of ART in any patient, health care workers conduct a complete assessment of the patient, starting with in-depth medical history followed by a head-to-toe physical examination, including WHO clinical staging. TB screening questionnaire was administered at baseline and during scheduled follow-up visits.

The country introduced a new guideline in 2012 to combat the poor enrolment of the pediatric population on ART that directed treatment of all HIV-positive children, under the age of 15 years, with suitable ART regimes [16]. Health care workers evaluated HIV-infected children for TB disease at the time of HIV diagnosis; at any time when they present with symptoms suggestive of TB during a scheduled follow-up visit or when they have a history of a new contact to an adult with TB. A standardized score chart, which is TB symptomscreening, was a tool used for screening of tuberculosis in children.

\section{Data management}

Primary data generated in the CTC was captured on facility-held information collection tools designated as CTC2 card. Information from CTC2 cards at the health facility level is aggregated either manually or electronically at different levels up to the national level. The manually aggregated data is electronically captured at the national level. Moreover, patient-level data from health facilities with electronic CTC2 databases is exported to the national level. In the end, electronically available aggregated data at the national level and 
patient-level data create a macro database designated as CTC3.

\section{Definition of variables}

Adult patients are referred to as those aged 15 years and older, as described in the National guideline for the Management of HIV and AIDS in Tanzania [16]. HIV clients "non-ART" are all patients who have enrolled in CTC but have not yet initiated ART. HIV clients "on ART" are all patients who have initiated ART. The date of enrolment in CTC was defined as the first date documented in the database, and enrolment year extracted from the first visit date. The date first initiated on ART was taken from the CTC record if it was recorded and otherwise defined as the first date recorded to receive ART. Patients were defined as the loss to follow-up (LTFU) if they had not attended any clinic in the 6 months preceding 31 December 2014 and were not known to have died. TB incidence was defined as a new bacteriologically confirmed case of TB by smear, GenXpert, or culture between1 January 2011 and 31 December 2014.

\section{Data analysis}

Abstracted data were analyzed using StataCorp 2015 (Stata Statistical Software: Release 14. College Station, TX: StataCorp LP). The individual-level data were used to calculate the prevalence, incidence rate, and risk factors for the occurrence of tuberculosis. The analysis included all individuals who attended CTC from 1 January 2011 to 31 December 2014. The prevalence of tuberculosis was calculated for the entire patient population and separately for each program year. Further analyses stratified the subjects by sex, age group, and ART status (ART and Non-ART).

Patient characteristics at the time of incidence of TB were described by the year using frequencies and percentages for categorical variables. Patients seen in 2011 were followed until one of the following happened: the first episode of TB, or censored due to death, lost-tofollow-up, or on 31 December 2014. We divided the interval into the years to obtain annual TB incidence. We calculated the TB incidence rate by dividing the total number of TB incidence by the 1000 person-year of observation. A multivariable Cox proportional hazards regression model was used to estimate hazard ratios adjusted for all covariates and 95\% confidence intervals (CI) for factors associated with TB incidence. KaplanMeier estimation methods were used to calculate the probabilities of cumulative TB incidence after enrolment into the clinic, stratified by baseline characteristics of interest.

\section{Results}

Data were extracted and analyzed from records of 527, 249 individuals with a total of $11,539,844$ clinical encounters enrolled in HIV care and treatment services between 2011 and 2014, with an average of 6 encounters per year (Table 1).

\section{Prevalence of tuberculosis}

The number of cases and prevalence of TB among HIV clients enrolled in care and treatment clinics in the period of 2011 to 2014 are summarized in Table 2. The overall prevalence was $2.2 \%$, with a peak of $2.5 \%$ in the year 2013. Noticeably higher TB prevalence was found among children < 15 years, which peaked at $3.2 \%$ in 2013. Overall, TB was more reported in males than in females, and the differences were consistent over the 4 years. The highest prevalence in males was 3.5\% observed in 2013. Throughout the 4 years, there was a relatively lower prevalence of TB among PLHIV on ART than those not on ART.

\section{Incidence of tuberculosis}

We analyzed the incidence of TB by following up on patients who visited the HIV clinics beginning in each of the years from 2011 to 2014. The outcome of interest was confirmed TB. Over the 4 years, there were 22,071 confirmed cases of TB among clients attending CTC (Table 3). The overall incidence of TB was around 16.7 (95\% CI 16.4-16.9) cases per 1000 person-years. The annual incidence rate per 1000 person-years was 17.0 (95\% CI 16.5-17.4) in 2011 and 14.9 (95\% CI 14.5-15.4) in 2014 , indicating a $12.4 \%$ decrease over the 4 years. The incidence rate was significantly lower among females, 13.9 (95\% CI 13.7-14.2) per 1000 person-years than males 22.8 (95\% CI 22.4-23.3) per 1000 person-years. The incidence rate of TB was fourfold more common in non-ART patients as compared to ART patients, being 47.2 (46.1-48.3) per 1000 person-years versus 12.8 (12.6-13.0) per 1000 person-years. The risk of developing TB was significantly lower in adults (hazard ration less 1) compared to children below 15 years and increased with stage of clinical HIV disease (hazard ration from 2 in stage 2 to 12 in stage 4) (Table 3).

Table 1 Number of individuals and clinic encounters in HIV care, treatment, and support program in Tanzania from 2011 to 2014

\begin{tabular}{lll}
\hline Program year & Number of individuals & Total clinic encounters \\
\hline 2011 & 427,117 & $2,560,290$ \\
2012 & 449,114 & $2,565,557$ \\
2013 & 461,857 & $3,004,427$ \\
2014 & 527,249 & $3,409,570$ \\
Total & & $\mathbf{1 1 , 5 3 9 , 8 4 4}$ \\
\hline
\end{tabular}


Table 2 Prevalence of TB among individuals enrolled in HIV care, treatment, and support program in Tanzania from 2011 to 2014

\begin{tabular}{|c|c|c|c|c|c|}
\hline \multirow[t]{2}{*}{ Characteristics } & 2011 & 2012 & 2013 & 2014 & Total \\
\hline & $\boldsymbol{N}(\%)$ & $\boldsymbol{N}(\%)$ & $\boldsymbol{N}(\%)$ & $\boldsymbol{N}(\%)$ & $\boldsymbol{N}(\%)$ \\
\hline Overall & $8765(2.1)$ & $9798(2.3)$ & $11,212(2.5)$ & $9857(1.9)$ & $39,632(2.2)$ \\
\hline \multicolumn{6}{|l|}{ Age group } \\
\hline$<15$ years & $687(2.1)$ & $784(2.3)$ & $1066(3.2)$ & $854(2.4)$ & $3391(2.5)$ \\
\hline$\geq 15$ years & $8078(2.1)$ & $9014(2.3)$ & $10,146(2.4)$ & $9003(1.9)$ & $36,241(2.2)$ \\
\hline \multicolumn{6}{|l|}{ Sex } \\
\hline Male & $3858(2.9)$ & $4474(3.2)$ & $5066(3.5)$ & $4681(2.8)$ & $18,079(3.1)$ \\
\hline Female & $4907(1.8)$ & $5324(1.8)$ & $6146(2.0)$ & $5176(1.5)$ & $21,553(1.7)$ \\
\hline \multicolumn{6}{|l|}{ ART status } \\
\hline ART & $1145(1.5)$ & $883(1.4)$ & $630(1.2)$ & $699(1.2)$ & $3357(1.3)$ \\
\hline Non-ART & $7620(2.3)$ & 8915 (2.4) & $10,582(2.6)$ & $9158(2.0)$ & $36,275(2.3)$ \\
\hline
\end{tabular}

\section{Cumulative probability of TB incidence}

Kaplan-Meier curves were used to assess the cumulative probability of TB incidence over time and stratified by baseline variables of age and sex. The overall probability of TB incidence was $50 \%$ by 2 years since enrollment and reached around $65 \%$ in 4 years. The hazard of TB incidence was highest in the first year of enrolment (Fig. 1).
The cumulative probability of TB incidences was similar between adults and children in the first 6 months, progressively increasing more in adults than children after 6 months. Two years after, the cumulative enrollment probability for $\mathrm{TB}$ incidence was $50 \%$ in children while it reached around 60\% among adults (Fig. 2). There was a clear difference in the cumulative probability of $\mathrm{TB}$

Table 3 Incidence of tuberculosis among individuals enrolled in HIV care, treatment, and support program in Tanzania in 2011 to 2014

\begin{tabular}{|c|c|c|c|c|}
\hline Variable & TB cases & 1000 person-years & TB incident rate/1000 person-years $(95 \% \mathrm{Cl})$ & Hazard ratio $(95 \% \mathrm{Cl})$ \\
\hline Overall & 22,071 & 1323.6 & $16.7(16.4-16.9)$ & - \\
\hline \multicolumn{5}{|c|}{ Year of diagnosis } \\
\hline 2011 & 5366 & 316.2 & $17.0(16.5-17.4)$ & 1 \\
\hline 2012 & 5254 & 317.9 & $16.5(16.1-17.0)$ & $1.07(1.02-1.14)$ \\
\hline 2013 & 6356 & 348.5 & $18.2(17.8-18.7)$ & $1.15(1.09-1.21)$ \\
\hline 2014 & 5095 & 342.3 & $14.9(14.5-15.4)$ & $0.84(0.80-0.89)$ \\
\hline \multicolumn{5}{|l|}{ Sex } \\
\hline Male & 9306 & 407.7 & $22.8(22.4-23.3)$ & 1 \\
\hline Female & 12,764 & 916.9 & $13.9(13.7-14.2)$ & $0.65(0.64-0.67)$ \\
\hline \multicolumn{5}{|l|}{ ART status } \\
\hline Non-ART & 7026 & 148.9 & $47.2(46.1-48.3)$ & 1 \\
\hline ART & 15,045 & 1152.7 & $12.8(12.6-13.0)$ & $0.47(0.46-0.49)$ \\
\hline \multicolumn{5}{|c|}{ HIV clinical stage } \\
\hline 1 & 844 & 180.0 & $4.7(4.3-5.0)$ & 1 \\
\hline 2 & 2306 & 300.1 & $7.7(7.4-8.0)$ & $2.31(2.09-2.55)$ \\
\hline 3 & 13,233 & 604.8 & $21.9(21.5-22.2)$ & $10.2(9.31-11.09)$ \\
\hline 4 & 5214 & 216.7 & $24.1(23.4-24.7)$ & $12.3(11.2-12.45)$ \\
\hline \multicolumn{5}{|c|}{ Age group (years) } \\
\hline$<15$ & 2034 & 97.5 & $20.8(20.0-21.8)$ & 1 \\
\hline $15-24$ & 1210 & 70.4 & $17.2(16.3-18.2)$ & $0.66(0.63-0.78)$ \\
\hline $25-34$ & 5514 & 323.1 & $16.9(16.4-17.3)$ & $0.78(0.75-0.81)$ \\
\hline $35-44$ & 7554 & 458.9 & $16.5(16.1-16.8)$ & $0.93(0.90-0.97)$ \\
\hline $45-54$ & 3990 & 253.9 & $15.7(15.3-16.2)$ & $0.94(0.90-0.98)$ \\
\hline $55+$ & 1754 & 116.9 & $15.0(14.3-15.7)$ & $0.87(0.83-0.92)$ \\
\hline
\end{tabular}




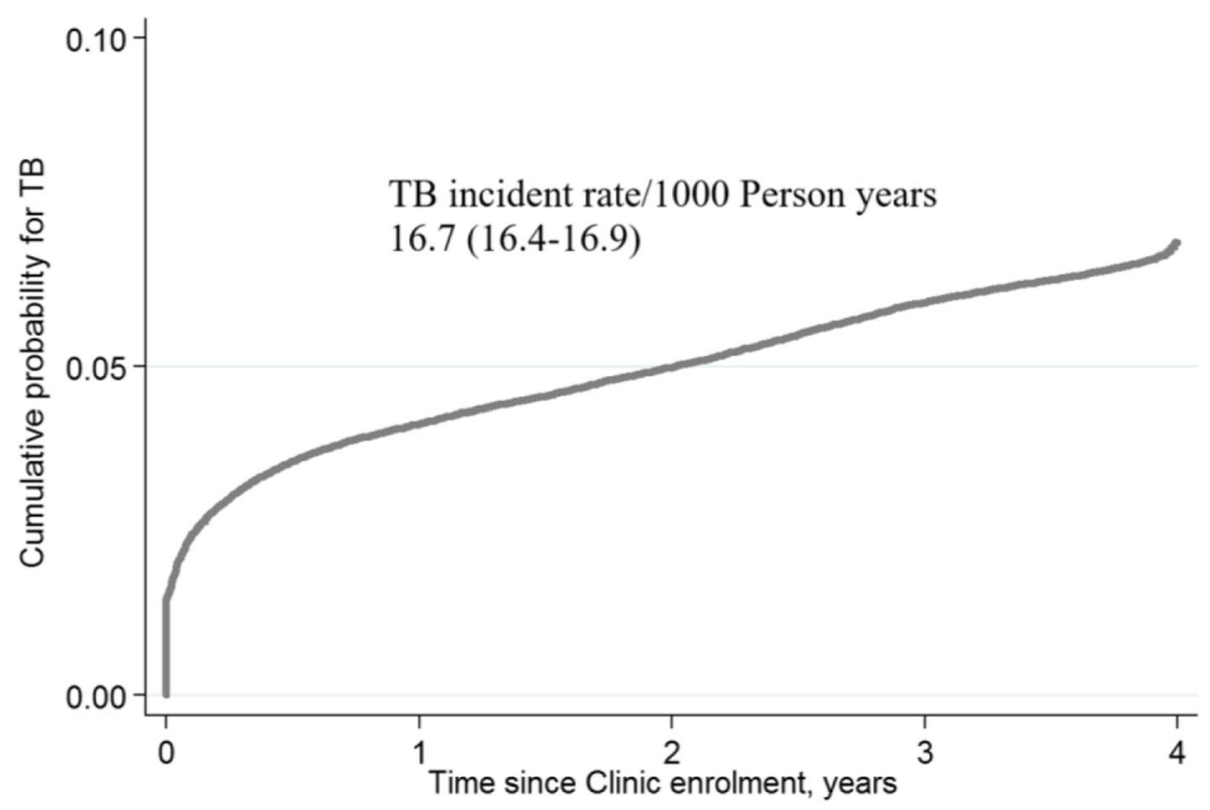

Fig. 1 Cumulative probability of TB incident after enrollment to HIV care and treatment

incidence between males and females. By 6 months, the cumulative probability of $\mathrm{TB}$ incidence among males reached $50 \%$ compared to $25 \%$ among females, who reached $50 \%$ after 3 years (Fig. 3 ).

\section{Discussion}

We conducted an assessment of the occurrence of a first episode of pulmonary tuberculosis (PTB), involving individuals whose first visits at HIV care and treatment services occurred between January 2011 and December
2014. As a result, the study included a total of 527,249 individuals with a total of $11,539,844$ clinical encounters at health facilities implementing TB and HIV collaborative activities. The overall TB incidence rate was around 16.7 (95\% CI 16.4-16.9) cases per 1000 person-years with annual incidence rate decreasing from 17.0 to 14.9 per 1000 person-years, representing around $12 \%$ decrease over the 4 years.

The observed incidence of TB in PLHIV on ART reported in this study (12.8 per 1000 person-years) is on

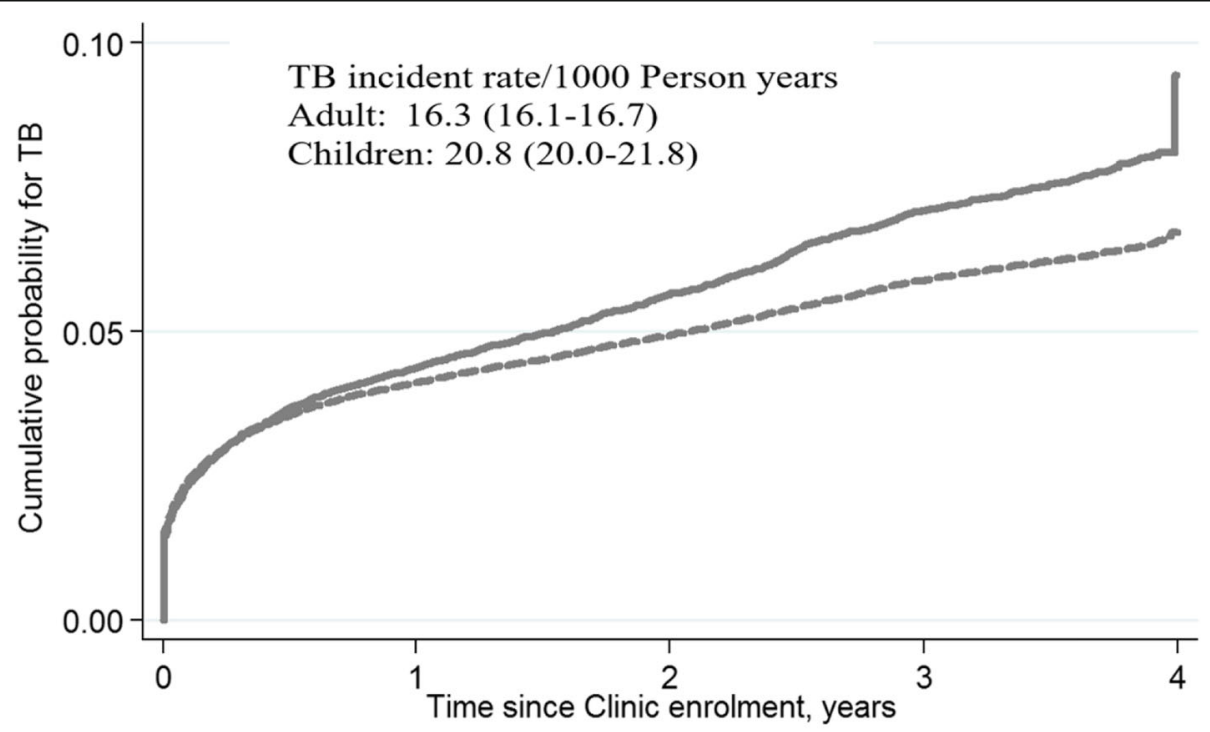

Adults - $-\infty$ Children

Fig. 2 Cumulative probability of TB incident after enrollment to HIV care and treatment by age 


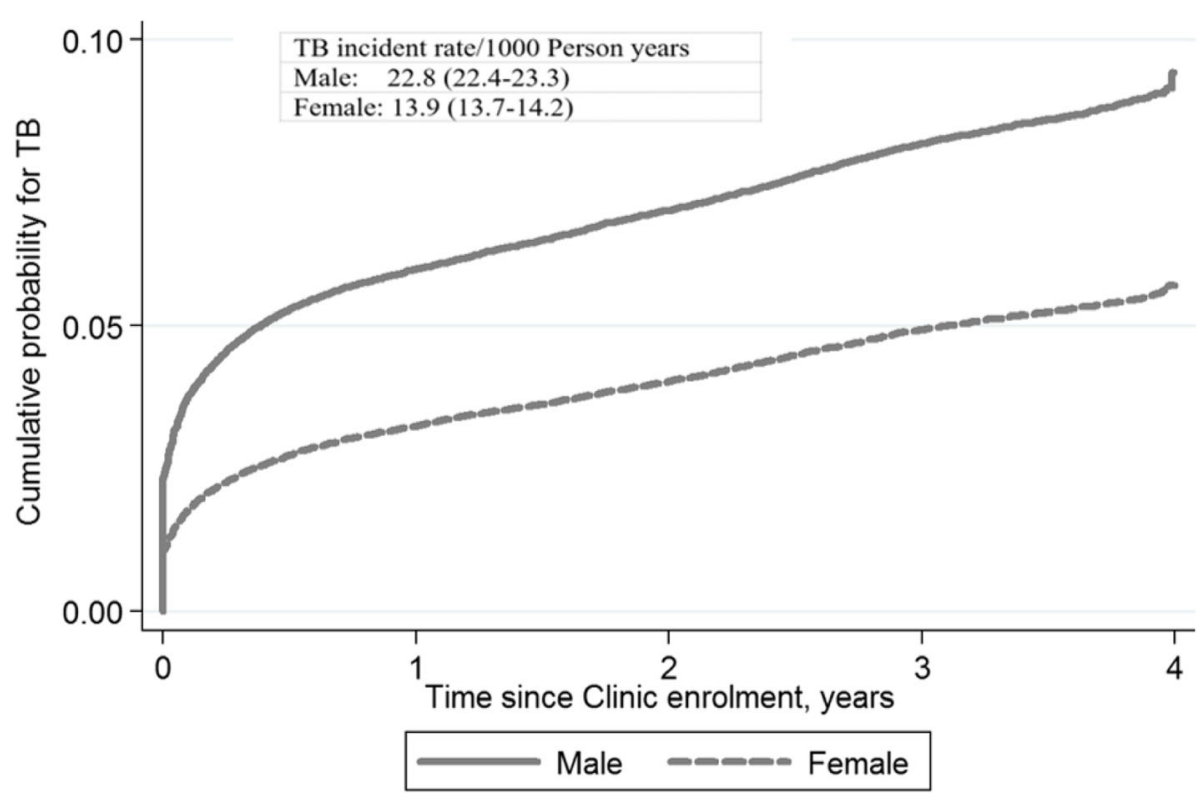

Fig. 3 Cumulative probability of TB incident after enrollment to HIV care and treatment by age and sex

the lower side compared to observed incidences in prior studies conducted among adults in Tanzania [17]. The finding may be a reflection of continuous improvement in HIV and TB collaborative activities and the reduction of TB incidence in HIV programs. In support, we observed in this analysis that in patients receiving ART, the decrease in TB incidence went from 13.5 (95\% CI 13.114.0) per 1000 person-years in 2011 to 11.0 (95\% CI $10.6-11.3$ ) in 2014 a decrease of $19 \%$ over the 4 years. In contrast, those not on ART, the TB incidence went from 33.3 (95\% CI 31.8-34.8) per 1000 person-years in 2011 to 104.9 (95\% CI 99.7-110.3) per 1000 person-years in 2014, a three-fold increase in the incidence of TB. The reported incidences in other parts of African countries range from 0.9 to 7.9 cases per $100 \mathrm{PY}$ [18-21].

As observed in this analysis and reported in other studies, the use of ART has a significant advantage on the reduction of incidence of TB, evidenced by a marked low incidence of TB among persons on ART compared to those not on ART $[17,22,23]$. The findings are conceivable because the TB infection and reactivation have been associated with the degree of immune suppression, which improves after the start of ART [24]. In individuals not on ART, HIV infection increases susceptibility to $\mathrm{TB}$ and is the most potent factor in transferring latent or recently acquired $\mathrm{TB}$ infection to active clinical diseases $[25,26]$. Our findings emphasize the need for TB preventive therapy, which has been found to reduce the risk of developing tuberculosis and prolongs survival [27].

The TB incidence in the current study was significantly associated with advanced HIV disease defined by
WHO clinical stages. Our findings are consistent with previous findings and support the known benefit of early HIV diagnosis and treatment [28]. There is a much higher risk of HIV and TB co-infected patients to develop active $\mathrm{TB}$ either from the latent infection or rapid progression of a new infection, especially in advanced HIV disease [29]. TB incidence as a result of immune reconstitution after initiation of ART is likely to occur in advanced HIV disease [12, 13]. Although this study did not record immune reconstitution inflammatory syndrome, the majority of $\mathrm{TB}$ incidence among patients with advanced HIV disease occurred within 2 months after ART initiation, as previously observed [12, 13]

The study found a higher risk of TB among males compared to females, which is comparable to other studies $[2,30,31]$. The most probable reason to explain this difference could be the biological differences in disease and disease presentation, which favors women [32, 33]. Furthermore, men are more likely to report predisposing factors for TB, like smoking than females [34]. PLHIV, aged below 15 years, had a significantly higher risk of TB incidence than adults. However, encouragingly, the observed overall incidence of TB in children (20.8 cases per $1000 \mathrm{PY}$ ) is less compared to findings from a previously reported cohort study in Tanzania (5.2 cases per 100 PY) [35]. This signifies the effort in increasing access to pediatric HIV and TB care and treatment in Tanzania [36].

The major strength of this study is that it drew on a large and nationally representative sample from a country with a significant burden of TB and HIV. It has provided some insights into the situation of TB in clinical 
services for HIV care and treatment in Tanzania. Nevertheless, the analysis excluded patients without bacteriological confirmation, which lead to underestimation of the magnitude of TB. Besides, many of our facilities may not be able to perform a bacteriological diagnostics test, which has high sensitivity and specificity, instead of depending on radiological and clinical diagnoses. The other limitation is that the data come from the electronic CTC database, which is used in the larger and better run clinics. The situation reported here might not be the same in smaller health facilities that have not provided electronic data.

\section{Conclusion}

The study found an overall decrease in the incidence of TB in PLHIV and demonstrated more among those on ART, adult, female, and low HIV clinical stage. Our results reinforce the recommendation of HIV test and treat, intensified $\mathrm{TB}$ case findings, and $\mathrm{TB}$ preventive therapy for those PLHIV without active TB.

\section{Abbreviations}

ART: Antiretroviral therapy; CTC: Care and treatment clinics; HIV: Human immunodeficiency virus; PLHIV: People living with HIV; TB: Tuberculosis; WHO: World Health Organization

\section{Acknowledgements}

We wish to acknowledge the contribution of all health care providers at District and Health care facility levels in generating and compilation of data at their respective levels of service delivery. We also wish to thank all staff from the Epidemiology Unit of the National AIDS Control Programme for the ultimate compilation and analysis of data at the national level.

\section{Authors' contributions}

GS, JN, SV, and TJ were involved in preparing the study protocol. GS was the overall coordinator of the study, while JN, SV, and TJ performed statistical analyses. MM, MIM, JM, AJ, AR, NM, AR, and WM were involved in various stages of study from reviewing the protocol, reviewing the results and preparation of the manuscript. All authors jointly prepared and approved the final manuscript.

\section{Funding}

Funding came from The Ministry of Health, Community Development, Gender, Elderly and Children (MHCDGC) through National AIDS Control Programme with further support from Centres for Disease Control (CDC) and World Health Organization (WHO).

\section{Availability of data and materials}

The raw data supporting the findings can be accessed on reasonable request to the Head of the Epidemiology Unit of the National AIDS Control Programme.

\section{Ethics approval and consent to participate}

The data was collected by health facilities providing HIV care and treatment services and managed by the Epidemiology Unit of National AIDS Control Programme using the National Guidelines for HIV Care and Treatment, in which ethical issues are strongly advocated.

\section{Consent for publication}

Not applicable

\section{Competing interests}

The authors declare that they have no competing interests.

\section{Author details}

1Department of Microbiology and Immunology, School of Medicine, Muhimbili University of Health and Allied Sciences, Dar es Salaam, Tanzania. ${ }^{2}$ National AIDS Control Programme, Ministry of Health, Community Development, Gender, Elderly and Children, Dar es Salaam, Tanzania. 3 London School of Hygiene and Tropical Medicine and National Institute for Medical Research, Mwanza, Tanzania.

Received: 30 March 2020 Accepted: 24 August 2020

Published online: 04 September 2020

\section{References}

1. Mungrue K, Beharry A, Kalloo J, Mahabir S, Maraj T, Ramoutar R, et al. Trends in HIV/TB co-infection in Trinidad and Tobago for the period 1998-2007. J Int Assoc Physicians AIDS Care. 2009;8(3):170-5.

2. BMd C, Monteiro AJ, RdJ PN, Grangeiro TB, Frota CC. Factors related to HIV/ tuberculosis co-infection in a Brazilian reference hospital. Braz J Infect Dis. 2008;12(4):281-6.

3. Alexander PE, De P. The emergence of extensively drug-resistant tuberculosis (TB): TB/HIV co-infection, multidrug-resistant TB and the resulting public health threat from extensively drug-resistant $T B$, globally and in Canada. Can J Infect Dis Med Microbiol. 2007;18(5): 289-91.

4. Organization WH. Global tuberculosis report 2015, vol. 2015; 2015

5. Organization WH. Global tuberculosis report 2018. 2018.

6. United Republic of Tanzania MoH, Community Development, Gender, Elderly and Children. National Tuberculosis and Leprosy Programme. Annual report. 2017.

7. Lawn SD, Harries AD, Anglaret X, Myer L, Wood R. Early mortality among adults accessing antiretroviral treatment programmes in sub-Saharan Africa. AIDS. 2008;22(15):1897-908.

8. Kumarasamy N, Venkatesh KK, Devaleenol B, Poongulali S, Yephthomi T, Pradeep A, et al. Factors associated with mortality among HIV-infected patients in the era of highly active antiretroviral therapy in southern India. Int J Infect Dis. 2009;14(2):e127-31.

9. Komati S, Shaw PA, Stubbs N, Mathibedi MJ, Malan L, Sangweni P, et al. Tuberculosis risk factors and mortality for HIV-infected persons receiving antiretroviral therapy in South Africa. AIDS. 24(12):1849-55.

10. Mwinga A, Hosp M, Godfrey-Faussett P, Quigley M, Mwaba P, Mugala BN, et al. Twice weekly tuberculosis preventive therapy in HIV infection in Zambia. AIDS. 1998;12(18):2447-57.

11. De Pinho AMS-LG, Harrison LH, Schechter M. Chemoprophylaxis for tuberculosis and survival of HIV-infected patients in Brazil. Aids. 2001;15(16): 2129-35.

12. Lawn SDBM, Wood R. Tuberculosis among HIV-infected patients receiving HAART: long term incidence and risk factors in a South African cohort. AIDS 2005;19:2109-16.

13. Badri MWD, Wood R. Effect of highly active antiretroviral therapy on incidence of tuberculosis in South Africa: a cohort study. Lancet. 2002; 359(9323):2059-64.

14. C TB. Interim policy on collaborative TB/HIV activities. Geneva: Switzerland; 2004

15. Organization WH. WHO policy on collaborative TB/HIV activities: guidelines for national programmes and other stakeholders. In: WHO policy on collaborative TB/HIV activities: guidelines for national programmes and other stakeholders 2012; 2012.

16. Ramadhani A, Josiah RM, Rwebembera A, Msuya EL, Swai R, Urassa P, et al. National Guidelines for the Management of HIV and AIDS. Ministry of Health and Social Welfare; 2012

17. Enju L, MAKUBI A, DRAIN P, SPIEGELMAN D, SANDO D, Nan L, et al. Tuberculosis incidence rate and risk factors among HIV-infected adults with access to antiretroviral therapy in Tanzania. AIDS (London, England). 2015; 29(11):1391.

18. Kufa T, Mabuto T, Muchiri E, Charalambous S, Rosillon D, Churchyard G, et al. Incidence of HIV-associated tuberculosis among individuals taking combination antiretroviral therapy: a systematic review and meta-analysis. PLoS One. 2014:9(11):e111209.

19. Dembele M, Saleri N, Carvalho AC, Saouadogo T, Hien AD, Zabsonre I, et al. Incidence of tuberculosis after HAART initiation in a cohort of HIV-positive patients in Burkina Faso. Int J Tuberc Lung Dis. 2010;14(3):318-23. 
20. Auld AF, Mbofana F, Shiraishi RW, Alfredo C, Sanchez M, Ellerbrock TV, et al. Incidence and determinants of tuberculosis among adults initiating antiretroviral therapy--Mozambique, 2004-2008. PLoS One. 2013;8(1):e54665.

21. Akanbi MO, Achenbach CJ, Feinglass J, Taiwo B, Onu A, Pho MT, et al. Tuberculosis after one year of combination antiretroviral therapy in Nigeria: a retrospective cohort study. AIDS Res Hum Retroviruses. 2013;29(6):931-7.

22. Taha M, Deribew A, Tessema F, Assegid S, Duchateau L, Colebunders R. Risk factors of active tuberculosis in people living with HIV/AIDS in southwest Ethiopia: a case control study. Ethiop J Health Sci. 2011;21(2):131-40.

23. Cui Z, Lin M, Nie S, Lan R. Risk factors associated with Tuberculosis (TB) among people living with HIV/AIDS: a pair-matched case-control study in Guangxi, China. PLoS One. 2017;12(3):e0173976.

24. van Asten L, Langendam M, Zangerle R, Aguado IH, Boufassa F, Schiffer V, et al. Tuberculosis risk varies with the duration of HIV infection: a prospective study of European drug users with known date of HIV seroconversion. AIDS. 2003;17(8):1201-8.

25. Girardi E, Raviglione MC, Antonucci G, Godfrey-Faussett P, IPPOLITO G. Impact of the HIV epidemic on the spread of other diseases: the case of tuberculosis. AIDS. 2000;14(3):S47-56.

26. Girardi E, Goletti D, Antonucci G, Ippolito G. Tuberculosis and HIV: a deadly interaction. J Biol Regul Homeost Agents. 2001;15(3):218-23.

27. Ayele HT, van Mourik MS, Debray TP, Bonten MJ. Isoniazid prophylactic therapy for the prevention of tuberculosis in HIV infected adults: a systematic review and meta-analysis of randomized trials. PloS one. 2015; 10(11):e0142290

28. Van Der Sande MA, Van Der Loeff MFS, Bennett RC, Dowling M, Aveika AA Togun TO, et al. Incidence of tuberculosis and survival after its diagnosis in patients infected with HIV-1 and HIV-2. AIDS. 2004;18(14):1933-41.

29. Albalak R, O'Brien RJ, Kammerer JS, O'Brien SM, Marks SM, Castro KG, et al. Trends in tuberculosis/human immunodeficiency virus comorbidity, United States, 1993-2004. Arch Intern Med. 2007;167(22):2443-52.

30. Kerr-Pontes LR, Oliveira FA, Freire CA. Tuberculose associada à AIDS: situação de região do Nordeste brasileiro. Rev Saúde Pública. 1997; 31(4):323-9.

31. Henn L, Nagel F, Dal PF. Comparison between human immunodeficiency virus positive and negative patients with tuberculosis in Southern Brazil. Mem Inst Oswaldo Cruz. 1999:94(3):377-81.

32. Karim F, Ahmed F, Begum I, Johansson E, Diwan V. Female-male differences at various clinical steps of tuberculosis management in rural Bangladesh. Int J Tuberc Lung Dis. 2008;12(11):1336-9.

33. Jimenez-Corona M-E, Garcia-Garcia L, DeRiemer K, Ferreyra-Reyes L, Bobadilla-del-Valle M, Cano-Arellano B, et al. Gender differentials of pulmonary tuberculosis transmission and reactivation in an endemic area. Thorax. 2006:61(4):348-53.

34. Smith GS, Van Den Eeden SK, Baxter R, Shan J, Van Rie A, Herring AH, et al. Cigarette smoking and pulmonary tuberculosis in northern California. J Epidemiol Community Health. 2015;69(6):568-73.

35. Li N, Manji KP, Spiegelman D, Muya A, Mwiru RS, Liu E, et al. Incident tuberculosis and risk factors among HIV-infected children in Tanzania. AIDS (London, England). 2013;27(8):1273-81.

36. Somi G, Majigo M, Manyahi J, Nondi J, Sambu V, Todd J, et al. Pediatric HIV care and treatment services in Tanzania: implications for survival. BMC Health Serv Res. 2017;17(1):540.

\section{Publisher's Note}

Springer Nature remains neutral with regard to jurisdictional claims in published maps and institutional affiliations.

Ready to submit your research? Choose BMC and benefit from:
- fast, convenient online submission
- thorough peer review by experienced researchers in your field
- rapid publication on acceptance
- support for research data, including large and complex data types
- gold Open Access which fosters wider collaboration and increased citations
- maximum visibility for your research: over 100M website views per year
At BMC, research is always in progress.
Learn more biomedcentral.com/submissions

